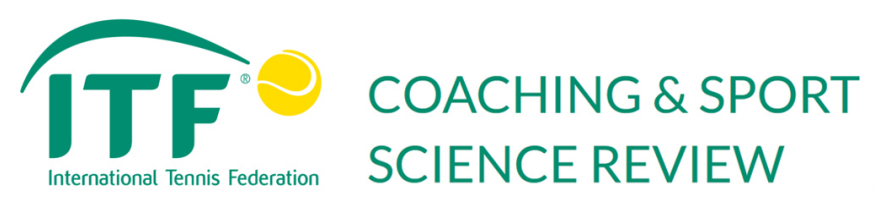

\title{
Fitness testing and players' development: Are we going the right way?
}

Jaime Fernandez-Fernandez, David Sanz-Rivas (ESP) and Hrvoje Zmajic (CRO)

ITF Coaching and Sport Science Review 2017; 71 (25): 12 - 15

\section{ABSTRACT}

The aim of this study was to analyse existing testing procedures and to establish initial recommendations and guidelines based on a survey which compared and analysed the testing procedures applied in the world leading tennis nations.

\author{
Key words: Physical testing, \\ development, performance \\ Received: 25 oct 2016 \\ Accepted: 21 Feb 2016 \\ Corresponding author: \\ Jaime Fernandez-Fernandez \\ Email: \\ jaime.fernandez@umh.es
}

\section{INTRODUCTION}

Tennis has evolved from a sport in which technical and tactical skills were the primary prerequisite for successful play into a sport that also requires a complex profile of physical performance (Fernandez- Fernandez, Sanz-Rivas, \& MendezVillanueva, 2009). To achieve a maximum improvement, the training programme should be prepared based on the analysis of the most important performance factors and the individual needs. The preparation of optimal training plans requires objective information, especially in the area of the physical training, including specific goals and measurable feedback in order to direct and evaluate the training process (Svensson \& Drust, 2005).

At present the tennis community generally accept that development of the player's performance is a long-term process which includes the regular application of physical performance testing (MacDougall, Wenger, \& Green, 1991; Reilly, Morris, \& Whyte, 2009). Successful performance in tennis demands a complex interaction of several physical components such as strength, agility, speed as well as aerobic and anaerobic endurance (Fernandez-Fernandez et al., 2009). In this regard, the assessment of the key physical and physiological parameters of performance is an integral part of sports science support for performance-oriented athletes. Thus, complexity exists in the identification of physiological determinants of performance in tennis.

It can be distinguished between single testing procedures and complex test batteries mapping the whole structure of physical performance. All testing procedures, single tests or complex test batteries should consider the following criteria:

1. Validity, reliability and objectivity (Reilly et al., 2009).

2. The results should be assessed in relation to standardized and representative norms / profiles.

3 . The frequency and dates for testing should be aligned with the training schedule (Fernandez-Fernandez, Ulbricht, \& Ferrauti, 2014).

In tennis, research has been conducted with athletes of various backgrounds (e.g., age, sex, performance level), and using different testing protocols, with the aim to identify the most influencing factors on tennis performance (i.e., ranking) (Birrer, Levine, Gallippi, \& Tischler, 1986; Girard \& Millet, 2009; William J Kraemer et al., 1995; E. Roetert, Piorkowski, Woods, \& Brown, 1995; P. Roetert \& Ellenbecker, 2007).

Results are not consistent, with some studies suggesting that physical qualities are weak predictors of overall tennis performance (Birrer et al., 1986) and others suggesting that specific qualities, such as agility (E. P. Roetert, Garrett, Brown, $\&$ Camaione, 1992) or speed and vertical power, are important for predicting tennis performance. Moreover, there is not a general agreement among the scientific community about which are the most useful tests in this sport and earlier studies did not systematically investigate (i.e. using a standardised test battery)

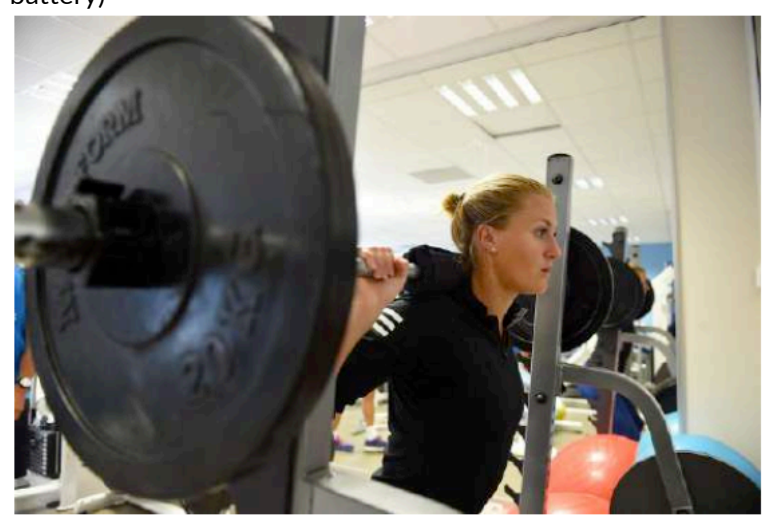

the impact of fitness characteristics on tennis performance across a large sample of young male and female tennis players (Ulbricht, Fernandez-Fernandez, \& Ferrauti, 2013). In the last few years, and in an attempt to standardize test procedures in tennis, several protocols have been documented, mainly by national tennis federations (Buckeridge et al., 2000; P. Roetert $\&$ Ellenbecker, 2007) (For more detailed information reading of (Fernandez-Fernandez et al., 2014) is recommended).

The aim of this study was to analyse existing testing procedures and to establish initial recommendations and guidelines based on a survey which compared and analysed the testing procedures applied in the world leading tennis nations.

FITNESS TESTING FOR 14\&UNDER PLAYERS - SURVEY FOR NATIONAL ASSOCIATIONS

The persons responsible for strength and conditioning in 14 National Associations filled out the survey consisted on 8 main points or questions, including:

1. A description of the physical tests used in their National Federations.

2. Description of measurement tools (i.e., simple (stopwatch)) or more sophisticated (light gates). 
3. If they were evaluating the testing results independently or by using group percentiles, etc.

4. The purpose of conditioning tests for the National association (i.e., Testing should focus coaches on developing particular abilities; track players' improvement; for talent identification).

5. How results are communicating (i.e., send the information to coach/player; fitness coach is creating individual training plans for conditioning; fitness coach is sending guidelines for individual training; creating a database and norms).

6. Observed benefits of applied system (i.e., Conditioning becameimportantpartofplayer'straining;Playersimprovedin observed abilities; Testing results are used for construction of the conditioning training plans).

7. Identified (system) challenges in applying conditioning tests. 8. Suggestions about the possible improvements of the applied system.

\section{RESULTS}

- Sixty-two percent of the Federations used simple measurement tools, while in the case of using more sophisticated tools, $62 \%$ used force platforms, all of the Federations asked used light cells, and $38 \%$ used isokinetic measurements or physiological assessments (i.e., treadmill tests with gas analyses).

- Fifty-five percent answered positively about the evaluation of the results independently or by using group percentiles, with $85 \%$ agreeing that testing should focus coaches on developing particular abilities, all of them used the tests for track player's improvement, and $62 \%$ for talent identification purposes.

- All the Federations sent the information to coaches/players and created databases and norm profiles, with $30 \%$ using the data to create individual training plans for conditioning, and $69 \%$ sending guidelines for individual training.

- Sixty-nine percent of the specialists asked felt that conditioning is an important part of player's training, and $77 \%$ reported that testing results are used for construction of the conditioning training plans and those players improved in observed abilities.

After summarizing the main physical tests used in the different National Federations, we have compared the tests depending on the physical quality analysed and if they were general (i.e., non-specific physical qualities) or tennis-specific tests (Table 1). Details of each test are not provided as some of them are confidential.

As part of the survey, there were also two "open" questions about challenges and possible improvements of the applied testing structures or systems. Below the reader will find the most interesting ideas reported by the different experts:

Identified (system) challenges in applying conditioning tests:

- Combine laboratory and on-court tests (Difficult to implement with consistency, given that laboratories are usually located far from the training centres).

- Not often able to conduct tests when players are rested due to camp/tournament scheduling. Therefore it is difficult to standardised protocols.

- The communication to the coach/player is always a challenge because there are many "truths" out there.

- Importance of test protocol.

- Difficulties in maintaining a systematic and periodic evaluation, (i.e., availability of centres and players, costs)

Possible improvements of the applied system

- Good software to analyse and evaluate results. The need of man-power to systematically collect, analyse and interpret data, as well as for creating reliable norms.
- Don't over interpret the results: growth and maturation itself can improve results.

- Players practice in what they get tested, so test what you believe is important to practice.

- To make physical trainers of the national clubs understand that a systematic evaluation of the players' training/practice through regular testing is necessary.

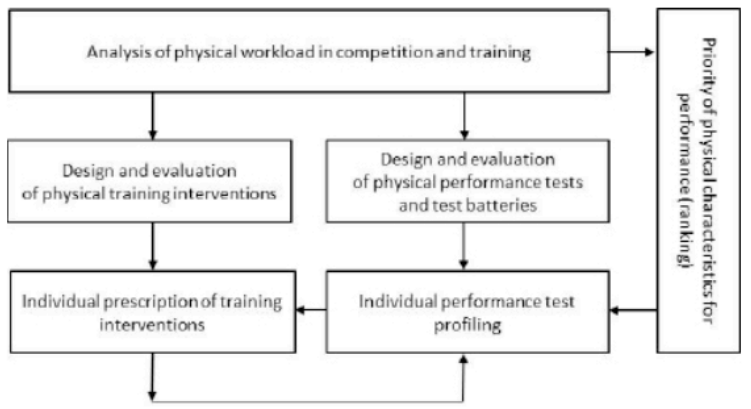

Figure 1. Schematic representation of the sport specific training optimization model (Fernandez-Fernandez et al., 2014)

\section{CONCLUSIONS AND THE "WAY FORWARD"}

The most important conclusion here is that although there is general agreement about the abilities that should be tested, at the same time there is a complete lack of agreement in terms of which are the most useful/recommended tests in tennis, when the physical/ physiological demands of the sports have been well described in the literature (Fernandez, MendezVillanueva, \& Pluim, 2006; Kovacs, 2007). The recommendation here would be to reach an agreement regarding test batteries which can follow the growth and maturation process.

According to the survey, self-made tests are still often used even though they lack validity (are they measure what we expect to measure?) and reliability (the results can be reproduced by repeating the tests under the same conditions), both important conditions a test must accomplish. In this regard, communication with the coach/ player is a challenge, because there are many "truths" out there, and the link between the scientific knowledge and the "reality" of the sport is sometimes missing.

We believe that including sport-scientists in fitness testing and profiling of players' physical and physiological capacities would ensure optimal application and interpretation of the test results. It would be also beneficial to create efficient databases and data analyses enabling comparison among countries, if an agreement regarding the previously mentioned issues is made. Based on the results obtained in the study, we believe that the development and application of physical performance assessment should be integrated into a complex scientific approach, which can be used to construct a long-term individual and sport specific training optimization model (Figure 1).

Figure 1. Schematic representation of the sport specific training optimization model (Fernandez-Fernandez et al., 2014) In this approach, a major first step is the knowledge about the workload profile during competition (i.e., athletes' movement patterns combined with physiological responses (i.e., heart rate (HR), sources of muscular energy)) to provide a better insight into the physiological demands of the sport (Bangsbo, Mohr, Poulsen, Perez-Gomez, \& Krustrup, 2006; FernandezFernandez et al., 2009; Gabbett, 2005; Kovacs, 2007; Stolen, Chamari, Castagna, \& Wisloff, 2005). This data can be used as external criteria for the validation (design and evaluation) of 
tennis specific test procedures, and standardized with representative data samples (e.g. different levels of performance, age and sex-groups) (Girard \& Millet, 2009; W. J. Kraemer et al., 2003).

This is directly related to the specificity training principle, which states that to target these performance characteristics or components, and elicit specific adaptations, training must be focussed on the desired elements of performance (Reilly et al., 2009). At the final stage of the schematic representation of the sport specific training optimization model, tennis players should complete a regular test

battery which allows an individual performance profiling and an individual prescription of training intervention. This process must be repeated in a regular feedback loop, while adapting training interventions to changes in physical performance.

\section{REFERENCES}

Bangsbo, J., Mohr, M., Poulsen, A., Perez-Gomez, J., \& Krustrup, P. (2006). Training and testing the elite athlete. J Exerc Sci Fit, 4(1), 1-13.

Birrer, R., Levine, R., Gallippi, L., \& Tischler, H. (1986). The correlation of performance variables in preadolescent tennis players. The Journal of sports medicine and physical fitness, 26(2), 137.

Buckeridge, A., Farrow, D., Gastin, P., McGrath, M., Morrow, P., Quinn, A., \& Young, W. (2000). Protocols for the physiological assessment of high-performance tennis players. Physiological Tests for Elite Athletes. Australian Sports Commission. Champaign, IL: Human Kinetics.

Fernandez-Fernandez, J., Sanz-Rivas, D., \& MendezVillanueva, A. (2009). A review of the activity profile and physiological demands of tennis match play. Strength \& Conditioning Journal, 31(4), 15.https://doi.org/10.1519/SSC.0b013e3181ada1c b

Fernandez-Fernandez, J., Ulbricht, A., \& Ferrauti, A. (2014). Fitness testing of tennis players: how valuable is it? Br J Sports Med, 48 Suppl 1, i22-31. doi:10.1136/bjsports-2013093152https://doi.org/10.1136/bjsports-2013093152

Fernandez, J., Mendez-Villanueva, A., \& Pluim, B. M. (2006). Intensity of tennis match play. Br J Sports Med, 40(5), 387-391; discussion 391. doi:10.1136/bjsm.2005.023168 https://doi.org/10.1136/bjsm.2005.023168

Gabbett, T. J. (2005). Science of rugby league football: a review. Journal of Sports Sciences, 23(9), 961976.https://doi.org/10.1080/0264041040002338 1

Girard, O., \& Millet, G. P. (2009). Physical determinants of tennis performance in competitive teenage players. J Strength Cond Res, 23(6), 1867-1872. doi:10.1519/JSC.0b013e3181b3df89https://doi.or g/10.1519/JSC.0b013e3181b3df89

Kovacs, M. S. (2007). Tennis physiology: training the competitive athlete. Sports Med, 37(3), 189-198. Retrieved from http:// www.ncbi.nlm.nih.gov/pubmed/17326695htps://d oi.org/10.2165/00007256-200737030-00001

Kraemer, W. J., Hakkinen, K., Triplett-Mcbride, N. T., Fry, A. C., Koziris, L. P., Ratamess, N. A., Knuttgen, H. G. (2003). Physiological changes with periodized resistance training in women tennis players. Med Sci Sports Exerc, 35(1), 157-168. doi:10.1249/01. mss.0000043513.77296.3fhttps://doi.org/10.1097 /00005768-200301000-00024

Kraemer, W. J., Triplett, N. T., Fry, A. C., Koziris, L. P., Bauer, J. E., Lynch, J. M., . . Nelson, R. C. (1995). An indepth sports medicine profile of women college tennis players. J Sport Rehabil, 4, 7998.https://doi.org/10.1123/jsr.4.2.79

MacDougall, J. D., Wenger, H. A., \& Green, H. J. (1991). Physiological testing of the high-performance athlete: Human Kinetics Books Champaign, IL.

Reilly, T., Morris, T., \& Whyte, G. (2009). The specificity of training prescription and physiological assessment: a review. J Sports Sci, 27(6), 575-589. doi:10.1080/02640410902729741https://doi.org/ 10.1080/02640410902729741

Roetert, E., Piorkowski, P., Woods, R., \& Brown, S. (1995). Establishing percentiles for junior tennis players based on physical fitness testing results. Clin Sports Med, 14(1), 1.https://doi.org/10.1016/S02785919(20)30254-4

Roetert, E. P., Garrett, G. E., Brown, S. W., \& Camaione, D. N. (1992). Performance profiles of nationally ranked junior tennis players. The Journal of Strength \& Conditioning Research, 6(4), 225231.https://doi.org/10.1519/00124278199211000-00006

Roetert, P., \& Ellenbecker, T. S. (2007). Complete conditioning for tennis: Human Kinetics Publishers.

Stolen, T., Chamari, K., Castagna, C., \& Wisloff, U. (2005). Physiology of soccer: an update. Sports Med, 35(6), 501-536.https://doi.org/10.2165/00007256200535060-00004

Svensson, M., \& Drust, B. (2005). Testing soccer players. Journal of Sports Sciences, 23(6), 601618.https://doi.org/10.1080/0264041040002129 4

Ulbricht, A., Fernandez-Fernandez, J., \& Ferrauti, A. (2013). Conception for Fitness Testing and individualized training programs in the German Tennis Federation. Sport-Orthopädie- Sport-Traumatologie-Sports Orthopaedics and Traumatology, 29(3), 180192.https://doi.org/10.1016/j.orthtr.2013.07.005

RECOMMENDED ITF TENNIS ACADEMY CONTENT (CLICK BELOW)

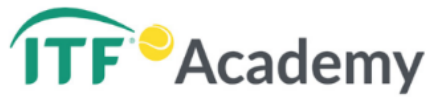

Copyright (c) Jaime Fernadez-Fernandez, David Sanz-Rivas and Hrvoje Zmajic 2016

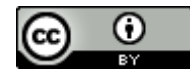

This text is under a Creative Commons BY 4.0 license

You are free to Share - copy and redistribute the material in any medium or format - and Adapt the content - remix, transform, and build upon the material for any purpose, even commercially under the following terms:

Attribution: You must give appropriate credit, provide a link to the license, and indicate if changes were made. You may do so in any reasonable manner, but not in any way that suggests the licensor endorses you or your use.

CC BY 4.0 license terms summary $\quad$ CC BY 4.0 license term 


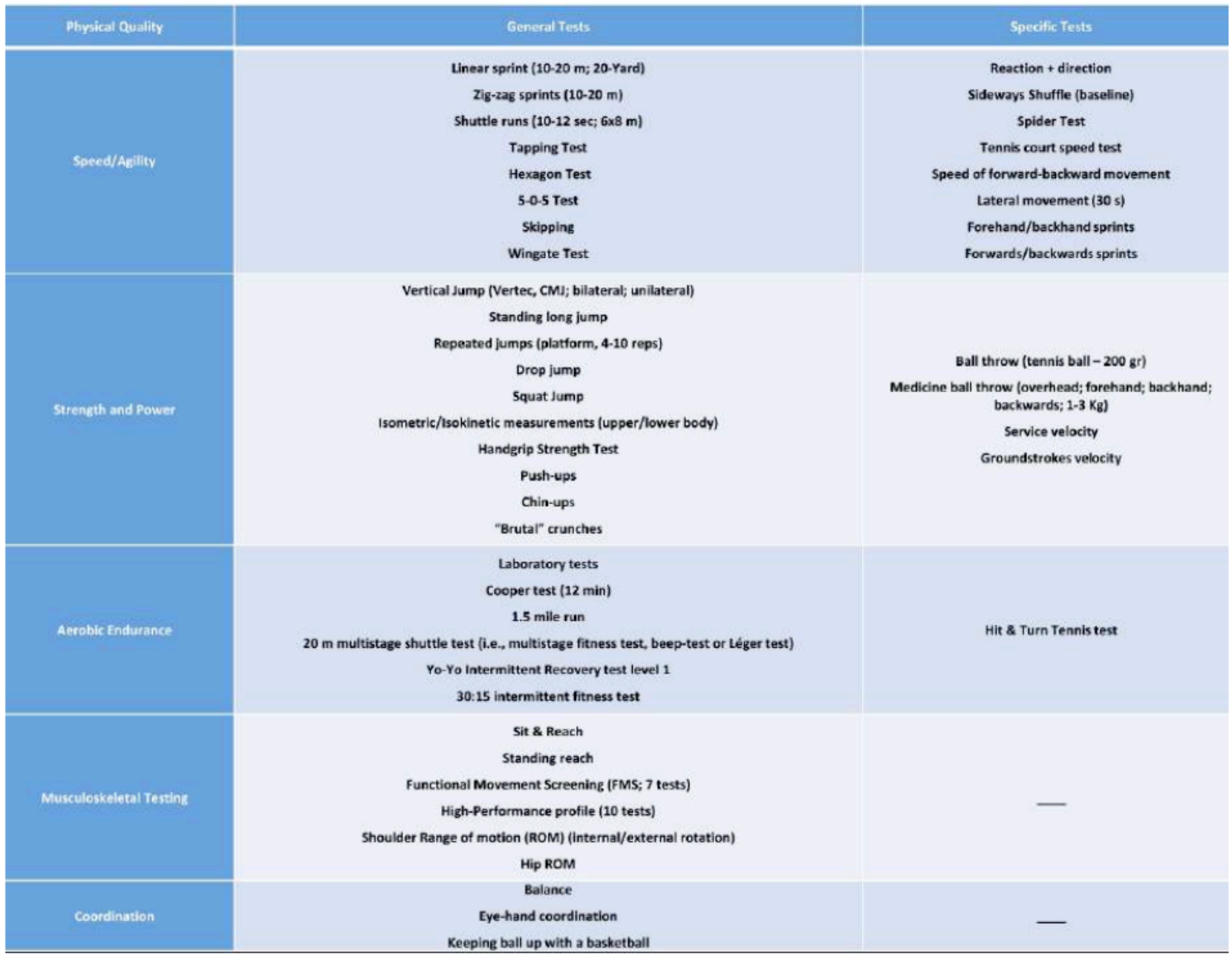

Table 1. Summary of the physical tests reported for the different National Tennis Federations participated in the survey. 